\title{
PENGARUH PENGGUNAAN MEDIA PUZZLE TERHADAP HASIL BELAJAR SISWA
}

\section{Sri Yunita, Ucup Supriatna}

STAI Al-Haudl Ketapang Kalimantan Barat, Indonesia

Email: sriyunita2297@gmail.com, kangucuptea@gmail.com

\begin{abstract}
Abstrak
Media pembelajaran merupakan komponen penting dalam proses pembelajaran untuk mencapai tujuan. Proses belajar itu terjadi karena adanya interaksi antara seseorang dengan lingkungannya. Salah satu pertanda seseorang telah belajar adalah adanya perubahan tingkah laku pada tingkat pengetahuan, keterampilan, atau sikap akibat pengalaman dan latihan. Kemampuan manusia untuk belajar merupakan karakteristik penting yang membedakan manusia dengan makhluk hidup lainnya. Pendidikan Nasional bertujuan untuk berkembangnya potensi peserta didik agar menjadi manusia yang beriman dan bertakwa kepada Tuhan Yang Maha Esa, berakhlak mulia, sehat, berilmu, cakap, kreatif, mandiri, dan menjadi warga negara yang demokratis serta bertanggung jawab. Penelitian ini bertujuan untuk mengetahui pengaruh penggunaan media puzzle terhadap hasil belajar. Pendekatan penelitian menggunakan pendekatan kuantitatif dengan desain one-group pretest-posttest design. Analisis data dengan melakukan uji paired sample $t$ tes. Hasil penelitian menyimpulkan bahwa ada pengaruh penggunaan media puzzle terhadap hasil belajar siswa. Implikasinya, penggunaan media pembelajaran merupakan hal yang penting untuk menjadi perhatian guru dalam proses pembelajaran.
\end{abstract}

Kata Kunci: pengaruh; media puzzle; hasil belajar

\section{Abstract}

Learning media is an important component in the learning process to achieve goals. The learning process occurs because of the interaction between a person and his environment. One of the signs that someone has learned is that there is a change in behavior at the level of knowledge, skills, or attitudes due to experience and practice. The ability of humans to learn is an important characteristic that distinguishes humans from other living things. National Education aims to develop the potential of learners to become human beings who believe and fear God Almighty, be noble, healthy, knowledgeable, capable, creative, independent, and become democratic and responsible citizens. This study aims to find out the influence of the use of puzzle media on learning outcomes. The research approach uses a quantitative approach with one-group pretest-posttest designdesign. Analyze the data by performing a paired sample t test. The results concluded that there is an influence on the use of puzzle media on students' learning outcomes. The implication is, the use of learning media is important to concern teachers in the learning process.

\begin{tabular}{ll}
\hline How to cite: & Yunita, S., \& Supriatna, U. (2021) Pengaruh Penggunaan Media Puzzle Terhadap Hasil Belajar \\
& Siswa, Syntax Idea, 3(8), https://doi.org/10.36418/syntax-idea.v3i8.1451 \\
E-ISSN: & 2684-883X \\
Published by: & Ridwan Institute
\end{tabular}


Keywords: effect; puzzle media, learning outcomes

\section{Pendahuluan}

Belajar adalah proses perubahan tingkah laku dari hasil pengalaman dan latihan (Fadillah, 2016; Mansur, 2018). Proses belajar itu terjadi karena adanya interaksi antara seseorang dengan lingkungannya. Salah satu pertanda seseorang telah belajar adalah adanya perubahan tingkah laku pada tingkat pengetahuan, keterampilan, atau sikap akibat pengalaman dan latihan. Kemampuan manusia untuk belajar merupakan karakteristik penting yang membedakan manusia dengan makhluk hidup lainnya.

Hasil belajar merupakan komponen dalam pendidikan yang merupakan indikator pencapaian tujuan pendidikan, karena hasil belajar diukur untuk mengetahui ketercapaian tujuan pembelajaran melalui proses belajar mengajar. Pendidikan Nasional bertujuan untuk berkembangnya potensi peserta didik agar menjadi manusia yang beriman dan bertakwa kepada Tuhan Yang Maha Esa, berakhlak mulia, sehat, berilmu, cakap, kreatif, mandiri, dan menjadi warga negara yang demokratis serta bertanggung jawab (Kholis, 2014).

Terkait hasil belajar peserta didik, berhasil atau tidaknya pembelajaran tidak terlepas dari tercapainya tujuan pendidikan, sehingga hasil belajar yang diukur sangat tergantung pada tujuan pendidikan (Sobandi, 2017). Tujuan pendidikan direncanakan untuk dapat dicapai dalam proses belajar mengajar. Akhir dari proses belajar adalah perolehan hasil belajar yang optimal. Hasil belajar yang diperoleh berupa skor nilai. Skor diperoleh siswa dari berbagai tes yang menggambarkan hasil pencapaian dari proses belajar yang dilakukan (Lestari \& Siswanto, 2015). Keberhasilan proses pembelajaran siswa dapat dilihat dari hasil belajar (Haslinda, 2020).

Berdasarkan pengamatan peneliti di SMP PGRI 3 Sungai Awan, rata-rata hasil belajar peserta didik masih dibawah Kriteria Ketuntasan Minimal (KKM) khususnya pada pelajaran Pendidikan Agama Islam. Permasalahan ini tidak terlepas dari pengaruh kurangnya kreativitas guru dalam menggunakan media, padahal media dapat membantu guru menggairahkan belajar siswa yang akan berdampak pada hasil belajar siswa (Alfan \& Sulistiyo, 2015).

Dalam pelaksanaan pembelajaran, guru dapat menggunakan berbagai macam media permainan yang bersifat edukatif agar memberikan motivasi kepada siswa sehingga menghasilkan tanggapan yang baik sehingga pengalaman yang diperoleh siswa dalam pembelajaran bukan sekedar permainan tetapi dapat memaknai permainan dalam pelajaran yang menimbulkan rasa senang dan mudah memahami pelajaran.

Media berperan sebagai perantara antara pemberi pesan dan informasi, dalam hal ini adalah guru kepada penerima pesan yaitu siswa (Asmariani, 2016). Dalam proses pembelajaran, informasi disampaikan oleh guru melalui media yang dapat berfungsi sebagai stimulus, yang disampaikan kepada siswa. Stimulus itu dapat berupa pernyataan dari guru atau disajikan dalam bentuk alat, bagan, dan gambar. Selanjutnya penerima pesan yaitu siswa akan memberikan respon atau reaksi dan akan terjadi interaksi antara guru, siswa dan lingkungan sekitarnya termasuk media pembelajaran. 
Puzzle merupakan alat permainan edukatif yang dapat merangsang kemampuan anak, dimainkan dengan cara membongkar pasangan kepingan puzzle (Gilli \& Dalle, 2019). Media puzzle adalah media permainan yang terdiri dari potongan gambar, kotakkotak, huruf, dan angka yang membentuk pola tertentu sehingga siswa ada keinginan menyelesaikan permainan secara cepat dan tepat (Maulida, Maulida, \& Zulfitria, 2018). Bermain puzzle merupakan hal yang sangat menarik yang membutuhkan kesababaran dalam merangsang anak untuk berpikir dan berimajinasi untuk menyusun potonganpotongan puzzle sehingga menjadi bentuk yang utuh. Dalam menyusun puzzle peserta didik harus memahami materi yang sudah diberikan agar dapat menjawab pertanyaan yang ada dan konsentrasi dalam mengikuti permainan (Husna, Sari, \& Halim, 2017).

Penelitian ini bertujuan melihat pengaruh penggunaan media puzzle terhadap Hasil Belajar Materi Iman kepada Allah SWT Siswa Kelas VII di SMP PGRI 3 Sungai Awan Tahun Pelajaran 2020/2021.

\section{Metode Penelitian}

Penelitian ini adalah menggunakan pendekatan kuantitatif dengan jenis one group pretest posttest design. Populasi penelitian adalah kelas VII A SMP PGRI Sungai Awan Ketapang sebanyak 22 orang. Teknik pengambilan sampel dengan non probablity sampling yaitu dengan teknik sampel jenuh artinya seluruh populasi dijadikan sampel berjumlah 22 orang. Data hasil belajar diambil dari pre test dan post test. Teknik analisis data menggunakan uji paired sample $t$ test dengan bantuan SPSS versi 25. Waktu pelaksanaan penelitian ini dilakukan pada bulan September sampai bulan Desember pada semester ganjil tahun pelajaran 2020/2021.

\section{Hasil dan Pembahasan}

\section{A. Hasil Penelitian}

Hasil analisis statistik deskriptif dapat dilihat pada tabel 1.

Tabel 1

Statistik Deskriptif

\begin{tabular}{lc|c|c|c|c}
\hline \multicolumn{5}{c}{ Descriptive Statistics } \\
\hline & N & Minimum & Maximum & Mean & Std. Deviation \\
\hline Hasil Pre-Test & 22 & 56 & 77 & 68.23 & 6.102 \\
\hline Hasil Post-Test & 22 & 80 & 92 & 85.55 & 3.764 \\
\hline $\begin{array}{l}\text { Valid N } \\
\text { (listwise) }\end{array}$ & 22 & & & & \\
\hline
\end{tabular}

Berdasarkan tabel 1 dapat dijelaskan bahwa dari 22 orang sampel penelitian rata-rata nilai pretest adalah 68,23 dan rata-rata hasil nilai posttest adalah 85,55 . Nilai terendah hasil pre test adalah 56 dan nilai tertinggi 77 . Hasil post test terendah 80 dan tertinggi 90.

Selanjutnya sebagai syarat uji parametrik dilakukan uji normalitas. Hasil uji normalitas dapat dilihat pada tabel 2. 
Tabel 2

Uji Normalitas

Tests of Normality

\begin{tabular}{lcccccr}
\hline & \multicolumn{3}{c}{ Kolmogorov-Smirnov } & \multicolumn{3}{c}{ Shapiro-Wilk } \\
\cline { 2 - 7 } & Statistic & df & Sig. & Statistic & df & Sig. \\
\hline Hasil Pre-Test & .148 & 22 & $.200^{*}$ & .939 & 22 & .189 \\
Hasil Post-Test & .114 & 22 & $.200^{*}$ & .948 & 22 & .290 \\
*. This is a lower bound of the true significance. & & & \\
a. Lilliefors Significance Correction & & & & \\
\hline
\end{tabular}

Berdasarkan tabel 2, nilai signifikansi hasil pretest dan nilai post test $>0,05$ yang dapat diterjemahkan data hasil tes berdistrubusi normal sehingga dapat dilakukan uji parametrik.

Hasil uji perbedaan (uji t) sampel berpasangan (paired sample test) dapat dilihat pada tabel 3 .

Tabel 3

Uji Perbedaan Sampel Berpasangan

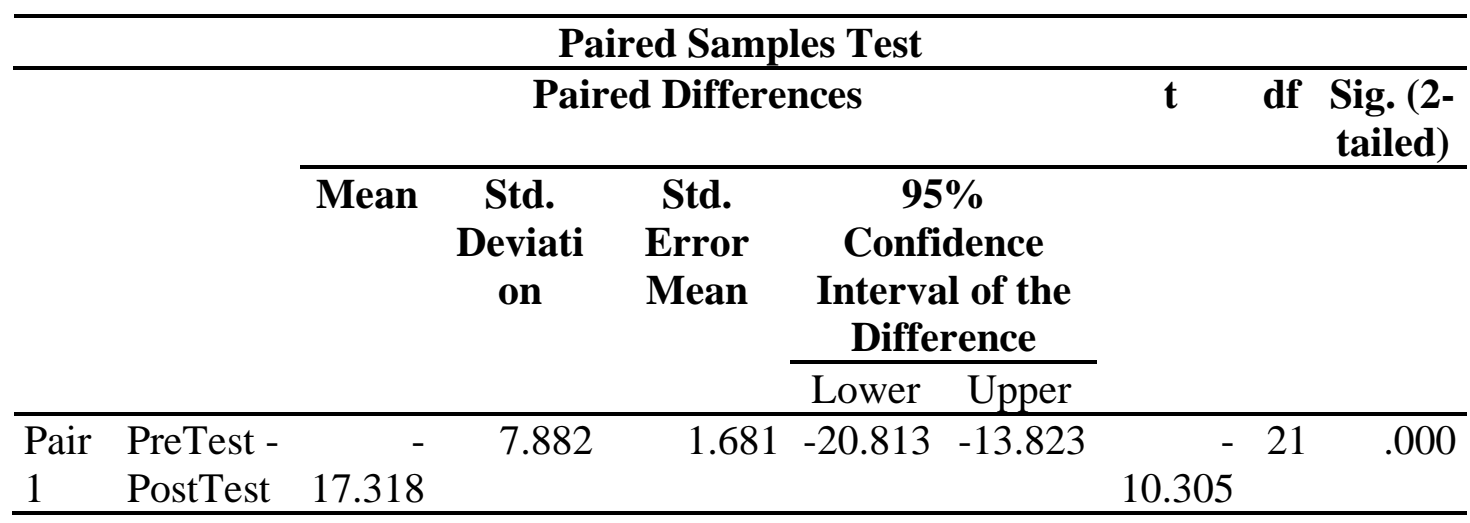

Berdasarkan tabel 3 hasil uji $\mathrm{t}$ sampel berpasangan menghasilkan nilai signifikasi $0,000<0,05$, dapat ditafsirkan ada perbedaan antara hasil pretest dan post test.

\section{B. Pembahasan}

Untuk mengetahui efektifitas proses pembelajaran dilakukan evaluasi hasil belajar peserta didik. Evaluasi merupakan suatu penilaian terhadap tingkat keberhasilan siswa mencapai tujuan pembelajaran. Evaluasi adalah suatu tindakan atau suatu proses untuk menentukan nilai keberhasilan seseorang setelah melaksanakan proses pembelajaran atau latihan (Suardipa \& Kadek Hengki, 2020).

Evaluasi menjadi bagian penting yang harus dilakukan dalam proses pembelajaran untuk mengetahui tingkat keberhasilan peserta didik dari suatu tindakan pembelajaran yang dilakukan. Dalam pelaksanaan pembelajaran menempuh tiga fase yaitu: pre test (tes awal), proses pembelajaran dan post test (tes akhir), materi enaluasi pembelajaran yang diteskan dalam post test sama dengan pre test (Hanafiyah, 2016). Oleh sebab itu, untuk melihat ada tidaknya pengaruh penggunaan 
media puzzle terhadap hasil belajar di SMP PGRI 3 Ketapang, dilakukan penelitian dengan menggunakan one group pretest posttest design.

Berdasarkan hasil penelitian terdapat perbedaan yang signifikan antara hasil belajar pre test dan post test setelah dilaksanakan pembelajaran menggunakan media puzzle dengan nilai signifikasi $0,000<0,05$. Hal ini sesuai dengan hasil penelitian sebelumnya, bahwa penggunaan media puzzle memberikan pengaruh signifikan terhadap hasil belajar siswa mata pelajaran IPA (Hastuti, 2017), ada pengaruh media puzzle terhadap hasil belajar siswa (Alawiyah, Suryana, \& Pranata, 2019) dan media pembelajaran puzzle dapat berpengaruh terhadap hasil belajar kognitif siswa (Nurpratiwiningsih \& Mumpuni, 2019).

Pemanfaatan media pembelajaran bertujuan untuk meningkatkan proses interaksi antara guru dan siswa dengan lingkungan belajarnya sehingga dapat mempengaruhi pencapaian hasil belajar yang lebih baik \{Formatting Citation\}.

Penggunaan puzzle mempunyai banyak kelebihan diantaranya meningkatkan interaksi siswa dalam pembelajaran, melatih kesabaran, melatih logika, melatih koordinasi mata dan tangan, meningkatkan keterampilan sosial, meningkatkan keterampilan motorik halus dan meningkatkan keterampilan kognitif. Penggunaan puzzle dapat meningkatkan keterampilan, pengetahuan dan respon siswa. Belajar sambil bermain merupakan metode yang baik dalam proses pembelajaran karena penyajian materi melibatkan siswa aktif dalam belajar dan bermain dan bersifat koolaboratif sehingga memberikan kontribusi pada peningkatan respon siswa dalam belajar. Selain itu, media puzzle bermanfaat dalam proses pembelajaran agar dapat membawa variasi dan perasaan senang bagi siswa dalam pengalaman belajar siswa serta memberikan umpan balik yang diperlukan dan dapat membantu siswa menemukan seberapa banyak yang mereka pelajari (Aisha, Hermansyah, \& Elvinawati, 2019).

Walapunpun demikian, menurut (Bahar \& Risnawati, 2019) penggunaan media puzzle mempunyai kelemahan antara lain, membutuhkan waktu yang relatif banyak, kelas menjadi ribut dan membutuhkan tingkat konsetrasi yang tinggi. Hal ini tentu harus menjadi perhatian dan kesiapan guru dalam menggunakan media puzzle.

Media pembelajaran adalah sebuah alat bantu atau pelengkap yang berfungsi untuk menyampaikan pesan dalam proses belajar mengajar. Media pembelajaran bukan satu-satunya penentu keberhasilan belajar siswa (Dadek, 2015; Ana Saragih, 2019), tetapi media pembelajaran menempati posisi yang penting di samping komponen-komponen yang lainnya.

\section{Kesimpulan}

Penggunaan media pembelajaran puzzle dapat meningkatkan hasil belajar siswa, hal ini dibuktikan dengan analisis hasil uji t sampel berpasangan terhadap hasil pre test dan post test siswa menghasilkan nilai signifikasi $0,000<0,05$. Dengan demikian dapat disimpulkan bahwa ada pengaruh penggunaan media puzzle terhadap hasil belajar 
siswa. Implikasinya adalah bahwa penggunaan media pembelajaran merupakan hal yang penting untuk menjadi perhatian guru dalam proses pembelajaran.

\section{BIBLIOGRAFI}

Aisha, Syafitri, Hermansyah, Amir, \& Elvinawati, Elvinawati. (2019). Perbandingan Hasil Belajar Siswa Menggunakan Pembelajaran Kooperatif Tife Team Games Tournament (TGT) Dengan Media Ular Tangga dan Media Puzzle Di Kelas XI SMAN 01 Bengkulu Tengah. Alotrop, 3(2), 132-138. Google Scholar

Alawiyah, Wiwi, Suryana, Yusuf, \& Pranata, Oyon Haki. (2019). Pengaruh Media Puzzle terhadap Hasil Belajar Siswa tentang Bangun Datar di Sekolah Dasar. Pedadidaktika: Jurnal Ilmiah Pendidikan Guru Sekolah Dasar, 6(1), 118129. Retrieved from https://ejournal.upi.edu/index.php/pedadidaktika/article/view/ 12799. Google Scholar

Alfan, Moch, \& Sulistiyo, Edy. (2015). Perbandingan Media Pembelajaran (Autoplay Media Studio) sebagai Alat Bantu Pembelajaran Memperbaiki CD Player Siswa Kelas XI Di SMK Negeri Surabaya. Jurnal Pendidikan Teknik Elektro, 4(1). Retrieved from https://jurnalmahasiswa.unesa.ac.id/index.php/jurnal-pendidikanteknik-elektro/article/view/10299. Google Scholar

Asmariani, Asmariani. (2016). Konsep media pembelajaran PAUD. Al-Afkar, V(1). Retrieved from http://www.ejournal.fiaiunisi.ac.id/index.php/alafkar/article/view/1 08/104.

Bahar, Bahar, \& Risnawati, Risnawati. (2019). Pengaruh Penggunaan Media Puzzle Terhadap Hasil Belajar Matematika Siswa Kelas III SD Di Kabupaten Gowa. Publikasi Pendidikan, 9(1), 77. Google Scholar

Fadillah, Ahmad. (2016). Analisis Minat Belajar dan Bakat Terhadap Hasil Belajar Matematika Siswa. Mathline : Jurnal Matematika Dan Pendidikan Matematika, 1(2), 113-122. Google Scholar

Gilli, Yatri, \& Dalle, Ambo. (2019). Keefektifan Penggunaan Media Gambar Berseri dalam Keterampilan Menulis Kalimat Sederhana Bahasa Jerman Siswa. Eralingua: Jurnal Pendidikan Bahasa Asing Dan Sastra, 3(1). Google Scholar

Hanafiyah, Hanafiyah. (2016). Penggunaan Media Puzzle Untuk Meningkatkan Hasil Belajar IPS Tentang Perkembangan Teknologi Produksi, Komunikasi dan Transportasi. Jurnal Ibtida'i, 3(2). Retrieved from http://jurnal.uinbanten.ac.id/index.php/ibtidai/article/view/163. Google Scholar

Haslinda, Haslinda. (2020). Penerapan Model Pembelajaran Think Talk Write Untuk Meningkatkan Hasil Belajar Bahasa Inggris Sub Tema Teks Interaksi Interpersonal Pada Kelas 8.1 SMPN 13 Bintan Semester Ganjil Tahun Ajaran 2019/2020. Syntax Idea, 2(10). Retrieved from https://www.jurnal.syntax-idea.co.id/index.php/syntax- 
idea/article/view/658.

Hastuti, Widya. (2017). Pengaruh Media Puzzle Terhadap Hasil Belajar IPA Konsep Daur Hidup Makhluk Hidup. Jurnal Pena, 4(1), 679-687. Google Scholar

Husna, Nurul, Sari, Adelila, \& Halim, Dan A. (2017). Pengembangan Media Puzzle Materi Pencemaran Lingkungan di SMP Negeri 4 Banda Aceh. In Jurnal Pendidikan Sains Indonesia (Vol. 05). Retrieved from http://jurnal.unsyiah.ac.id/jpsi. Google Scholar

Kholis, Nur. (2014). Paradigma Pendidikan Islam Dalam Undang-Undang Sisdiknas 2003. Jurnal Kependidikan, 2(1), 71-85. Google Scholar

Lestari, Isnania, \& Siswanto, Budi Tri. (2015). Pengaruh pengalaman prakerin, hasil belajar produktif dan dukungan sosial terhadap kesiapan kerja siswa SMK. Jurnal Pendidikan Vokasi, 5(2), 183-194. Google Scholar

Mansur, Rosichin. (2018). Lingkungan Yang Mendidik Sebagai Wahana Pembentukan Karakter Anak. Vicratina: Jurnal Pendidikan Islam, 2(2), 33-46. Retrieved from http://riset.unisma.ac.id/index.php/fai/article/view/730. Google Scholar

Maulida, Achlisha, Maulida, Achlisha, \& Zulfitria, Zulfitria. (2018). Pengembangan Kecerdasan Interpersonal Anak Autis Melalui Pemanfaatan Media Puzzle Pada Siswa Kelas 2 Sekolah Dasar. Jurnal Holistika, 1(2). Retrieved from https://jurnal.umj.ac.id/index.php/holistika/article/view/2506. Google Scholar

Nurpratiwiningsih, Laelia, \& Mumpuni, Atikah. (2019). Pengaruh Media Puzzle Terhadap Hasil Belajar Pada Pembelajaran IPS Di Sekolah Dasar. In Jurnal Kontekstual (Vol. 01). Retrieved from http://dev.umus.ac.id/index.php/kontekstual/ article/view/52. Google Scholar

Sobandi, Rizki. (2017). Pengaruh Motivasi Belajar Terhadap Hasil Belajar Bahasa Indonesia Pada Siswa Kelas VIII MTs. Negeri 1 Pangandaran. DIKSATRASIA, 1(2), 306-310. Retrieved from https://jurnal.unigal.ac.id/index.php/diksatrasia/article/view/634. Google Scholar

Suardipa, I. Putu, \& Kadek Hengki, Primayana. (2020). Peran desain evaluasi pembelajaran untuk meningkatkan kualitas pembelajaran. Jurnal Widyacarya, 4(2). Retrieved from http://jurnal.stahnmpukuturan.ac.id/index.php/widyacarya/article/vi ew/796. Google Scholar

Surtika, Tika, Sumardi, Sumardi, \& Yasbiati, Yasbiati. (2020). Pengaruh Media Puzzle Huruf Terhadap Kemampuan Mengenal Huruf Pada Anak Kelompok A Di TK ArRahman Kecamatan Sukahening. Jurnal Paud Agapedia, 3(1), 101-111. Google Scholar

\section{Copyright holder:}


Sri Yunita, Ucup Supriatna

Sri Yunita, Ucup Supriatna (2021)

First publication right:

Syntax Idea

This article is licensed under:

(c) (i) (2) 